\title{
Correspondence
}

\section{Cranial nerve palsy following retrobulbar anaesthesia}

SIR, Retrobulbar injection of anaesthetic agents is seldom associated with serious sequelae. Complications such as retrobulbar haemorrhage, central retinal artery occlusion, scleral perforation, grand mal seizures, and cardiopulmonary arrest have, however, been described. We wish to report an additional complication of retrobulbar anaesthesia: temporary contralateral second and third cranial nerve dysfunction accompanied by a depressed sensorium.

\section{Case report}

A 66-year-old white male without significant past medical history complained of sudden loss of his inferior visual field in his left eye. Best-corrected visual acuity was $20 / 30$ in the right eye and 20/40 in the left eye. Pupils were equal round and reactive to light and versions were full. Slit-lamp biomicroscopy of the anterior segments revealed early nuclear sclerosis. Tensions by applanation tonometry were $14 \mathrm{~mm} \mathrm{Hg}$ in both eyes. Funduscopic examination was remarkable for lattice degeneration in both eyes and a superior retinal detachment in the left eye. While dilated, retrobulbar anaesthesia was administered to the left eye using $3 \mathrm{ml}$ of $2 \%$ lignocaine without epinephrine and a disposable ultrasharp tip needle. Air was then injected into the left eye to tamponade the retinal break located at the 12 o'clock meridian. After the procedure was completed the patient complained of decreased vision in his other eye and became disorientated. Visual acuity in the right eye was hand motion. The patient was unable to elevate, depress, or adduct the eye.

Right cranial nerves four and six were intact. Blood pressure, pulse, and respiratory rate were stable, and there were no other neurological findings except for an altered mental status. He was both incoherent and disorientated to time and place. Approximately one hour after the onset of symptoms the patient's visual acuity improved to $20 / 40$ in the right eye, and versions were again full. He became coherent and orientated to time and place.

\section{Discussion}

Injection of local anaesthetics into the optic nerve sheaths and subsequently into the intracranial cavity has been proposed as the mechanism of central nervous system complication following retrobulbar anaesthesia. In five patients who underwent retrobulbar injection, orbitography demonstrated radio-opaque dye penetrating the optic nerve sheaths and tracking into the subdural space. ${ }^{1}$ The contrast material outlined the optic nerve and extended through the optic canal into the middle cranial fossa. In all cases the injection was believed to be uncomplicated. This pathway has similarly been demonstrated in cadavers. ${ }^{2}$

Animal studies have shown that direct injection of anaesthetic into the optic nerve results in nerve fibre degeneration. ${ }^{3}$ Paulter et al. reported two cases of marked visual loss resulting from retrobulbar injections presumably into the optic nerve sheath. ${ }^{+}$Callahan suggests that the likelihood of penetrating the optic nerve is increased when disposable needles are used. ${ }^{5}$ These needles are ultrasharp, and consequently it is difficult to appreciate the resistance of the optic nerve sheath.

The patient presented illustrates contralateral second and third cranial nerve dysfunction as a complication of retrobulbar anaesthesia induced with an ultrasharp needle. We believe a significant concentration of anaesthetic reached the optic nerve chiasm and/or contralateral optic nerve to block nerve conduction. The contralateral nerve palsy resolved once the anaesthetic was metabolised. The patient's disorientation suggests that the anaesthetic agent also entered the subarachnoid space and the cerebrospinal fluid. Recently, Antoszyk and Buckley reported three cases of contralateral second and third nerve palsy, ${ }^{6}$ and Friedberg and Kline described two cases of contralateral second nerve palsy ${ }^{7}$ following retrobulbar anaesthesia using ultrasharp needles. Many authors recommend the use of blunt tip needles and having the patient look straight ahead or down and outward during retrobulbar injection to minimise the chance of penetrating the optic nerve sheath. ${ }^{56} \mathrm{We}$ feel this will reduce the incidence of complications following retrobulbar injection.

RAND RODGERS

Mount Sinai School of Medicine

JUAN ORELLANA and Beth Israel Medical Center,

New York

USA

\section{References}

1 Reed JW, MacMillan AS, Lazenby GW. Transient neurologic complications of positive contrast orbitography. Arch Ophthalmol 1969; 81: 508-11.

2 Drysdale DB. Experimental subdural retrobulbar injection of anaesthesia. Ann Ophthalmol 1984; 16: 716-8.

3 Linn JG Jr. The effects of injection of anesthetic solutions into the optic nerve. Am J Ophthalmol 1957; 43: 471.

4 Paulter SE, Grizzard WS, Thompson LN, Wing GL. Blindness following retrobulbar injection into the optic nerve. Ophthalmic Surg 1986; 17: 334-7.

5 Callahan A. Ultrasharp disposable needles. Am J Ophthalmol 1966; 62: 173 .

6 Antoszyk AN, Buckley EG, Contralateral decreased visual acuity and extraocular muscle palsies following retrobulbar anesthesia. Ophthalmology 1986; 93: 462-5.

7 Friedberg HL, Kline OR Jr. Contralateral amaurosis after retrobulbar injection. Am J Ophthalmol 1986; 101: 688-90.

\section{Branch retinal arteriolar occlusion with chicken-pox}

SIR, A 19-year-old male who had developed the typical rash of chicken-pox three days previously was referred by his general practitioner after noticing a 'haze' in the nasal field of his left eye that day. On examination his visual acuity was $6 / 4$ in each eye unaided. Examination of his visual fields to confrontation revealed a left inferonasal quadrantic defect. The eyes were quiet and the pupillary responses were normal. Fundal examination revealed a left superotemporal branch arteriole occlusion, with a corresponding area of 


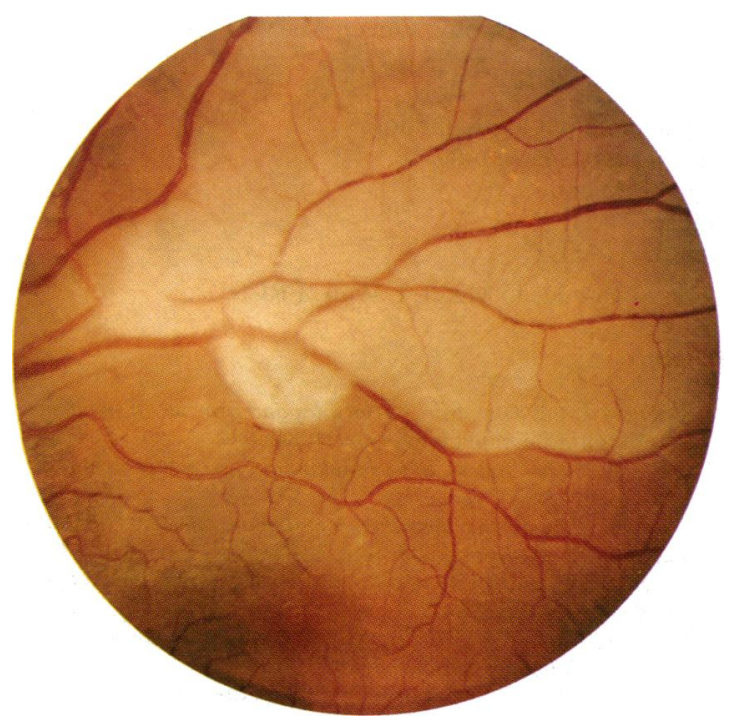

Fig. 1 Left fundus on admission.

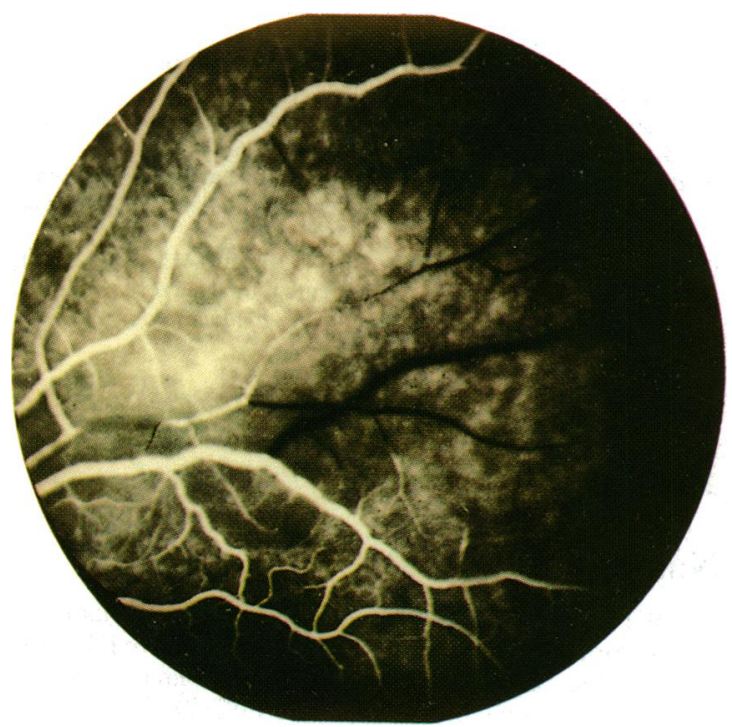

Fig. 2A Early fluorescein angiogram of left fundus.

oedema (Fig. 1). Immediate treatment with intravenous acetazolamide and eye massage proved unsuccessful. General examination was unremarkable, apart from a just palpable liver which resolved within five days. The following investigations gave normal results: full blood count and platelets, erythrocyte sedimentation rate, plasma viscosity, protein electrophoresis, fasting glucose and lipids, serology for syphilis, and urine analysis. Liver function tests revealed raised aspartate transaminase and $\gamma$-glutamyl transferase levels, but these fell markedly in five days and were entirely normal after a further week. Fluorescein angiography (Figs. $2 \mathrm{~A}, \mathrm{~B})$ confirmed the arteriolar obstruction with delayed filling of the corresponding vein. Late films demonstrated a

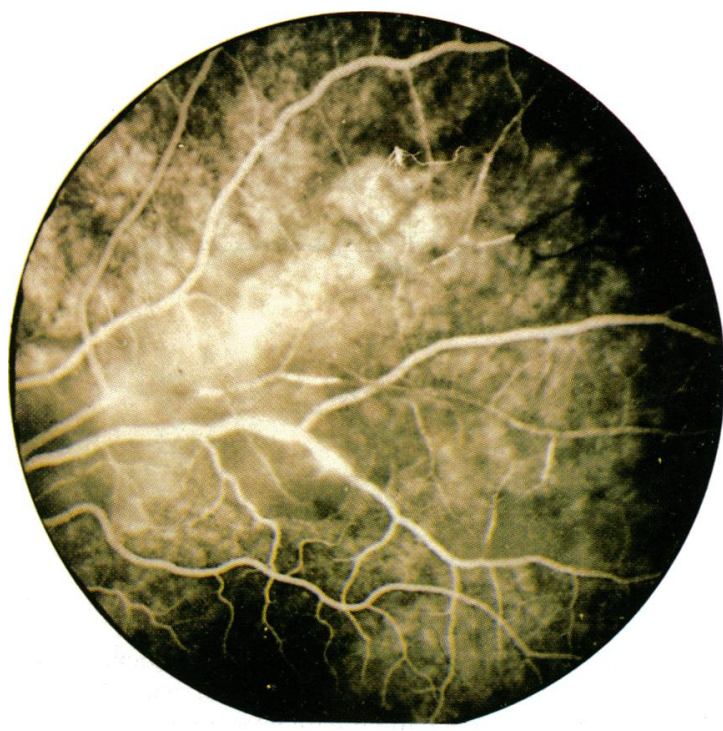

Fig. 2B Late fluorescein angiogram of left fundus.

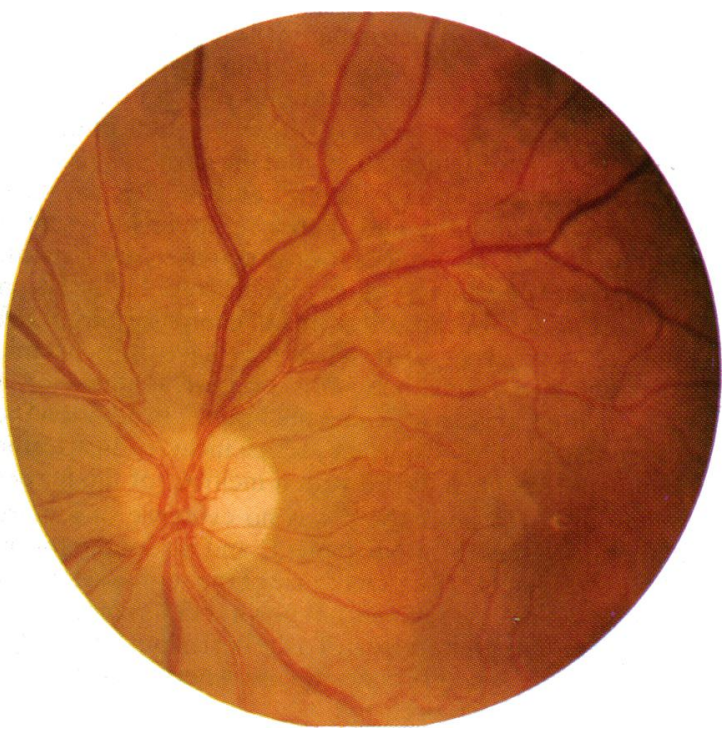

Fig. 3 Left fundus five months later.

slight leakage of dye around that vein, but we did not consider this signified a focal vasculitis.

The retinal oedema settled over the subsequent four months, though the appearance of the arteriole remained the same (Fig. 3), and a visual field test after five months showed that the defect remained unchanged (Fig. 4). Throughout this period his central visual acuity was unaffected.

\section{Discussion}

Serious complications following chicken-pox are fortunately rare $^{\prime}$ and the published reports of visual disturbances 


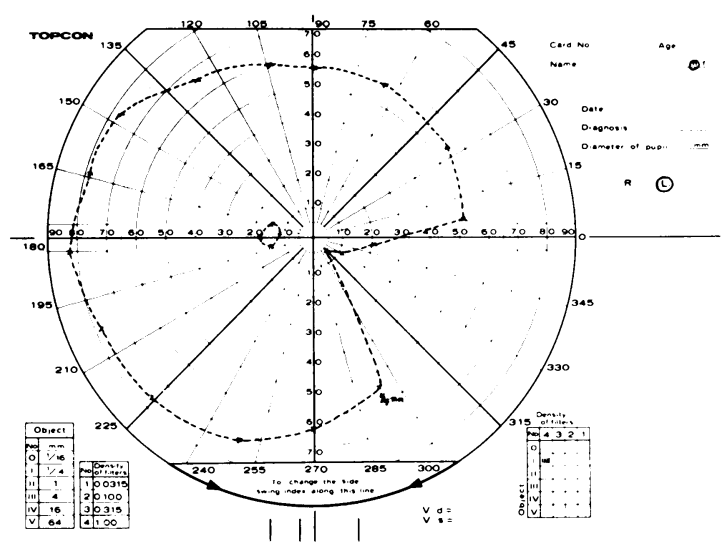

Fig. 4 Left visual field five months later.

occuring with it are few. ${ }^{2}$ One case was associated with unilateral ${ }^{3}$ and two with bilateral ${ }^{45}$ optic nerve involvement, and one other was in a patient with bilateral papillitis and a unilateral macular lesion, ${ }^{6}$ but all reported a good visual recovery. The only report of a permanent visual field defect ${ }^{7}$ was in a 16-year-old girl, occurring on the fourth posteruptive day. This is similar to our patient, who developed a field defect three days after the onset of his rash. In that report the field defect was associated with segmental optic disc pallor followed by pigmentation, and the authors suggested that this was caused by a focal optic neuritis. This may have had an ischaemic basis and therefore could represent a similar process to the arteriolar obstruction in our patient. Although there are no reports of retinal arteriolar occlusion associated with varicella zoster, many complications of the closely related herpes zoster virus may have an ischaemic basis, ${ }^{8}$ either a retinal vasculitis or perivasculitis ${ }^{9}$ or a granulomatous angiitis affecting the brain. ${ }^{10}$ In addition the acute retinal necrosis syndrome, which includes an arteritic component, has been linked with a member of the herpes virus group. ${ }^{11}$ However there was no evidence of a more widespread vasculitis in our patient, and no source for an embolus was found. The exact cause of the retinal arteriolar occlusion in this case remains unknown, but its coincidence with chicken-pox is interesting. To the best of our knowledge this is only the second reported case where a permanent visual field defect has occurred.

Our grateful thanks are due to Mr D L Hunter for kindly allowing us to report this case and for reviewing the manuscript, and to Miss Yvonne Bartlett of the Department of Medical Photography, Queen Mary's Hospital, Sidcup, Kent. C E HUGKULSTONE

Department of Ophthalmology, L L WATT

Queen Mary's Hospital,

Frognal Avenue,

Sidcup,

Kent DA 14 6LT.

Correspondence to Miss L L Watt, FRCS.

\section{References}

1 Macleod J, ed. Davidson's principles and practice of medicine. Edinburgh: Churchill Livingstone, 1984: 730.

2 Duke-Elder S. System of ophthalmology. London: Kimpton. 1976; $15: 167$.

3 Ford FR. Diseases of the nervous system in infancy, childhood and adolescence. Springficld, Illinois: Thomas, 1966: 576-77.

4 Hatch HA. Bilateral optic neuritis following chickenpox. J Pediatr 1949; 34: 758-9.

5 Liioi JA, Aiello MV. Bilateral papilloedema with chickenpox. J Pediatr Ophthalmol Strabismus 1970; 7: 155.

6 Copenhaver M. Chickenpox with retinopathy. Arch Ophthalmol 1966; 75: 199.

7 Taylor DSI, ffytche TJ. Optic disc pigmentation associated with a field defect following chickenpox. J Pediatr Ophthalmol Strabismus 1976; 13: 80-3.

8 Liesegang TJ. The varicella zoster virus: systemic and ocular features. J Am Acad Dermatol 1984; 11 : 165-91.

9 Naumann G, Gass JDM, FC.tt RL. Histopathology of herpes zoster ophthalmicus. Am J Ophthalmol 1968; 65: 533-41.

10 Blue MC, Rosenblum WI. Granulomatous angiitis of the brain with herpes zoster and varicella encephalitis. Arch Pathol Lab Med 1983; 107: 126-8.

11 Culbertson WW, Blumenkranz MS, Haines H, Gass JDM Mitchell KB, Norton EWD. The acute retinal necrosis syndrome Part 2: Histopathology and etiology. Ophthalmology 1982; 89: 1317-25.

\section{Notes}

\section{Names omitted}

SIR, We apologise for having omitted in error the names of two coworkers, Gisèle Soubrane, MD, and Peirre Dhermy, $\mathrm{MD}$, in the paper entitled Adenocarcinoma of retinal pigment epithelium' Br J Ophthalmol 1987; 71: 516-20. The correct list of authors should have been: C Ramahefasolo, G. Soubrane, P Dhermy, V Godel, L Regenbogen, G Coscas. 